\title{
Response surface optimization of biodiesel yield from pre-treated waste oil of rendered pork from a food processing industry
}

\author{
Arjun C. Gumahin'1, Jounnever M. Galamiton', Meljane J. Allerite', Rohoney S. Valmorida', Jay-R L. Laranang', \\ Val Irvin F. Mabayo ${ }^{1^{*}} \mathbb{0}$, Renato O. Arazo ${ }^{1,2}$ and Alexander L. Ido ${ }^{1,2}$
}

\begin{abstract}
In this study, the waste oil of rendered pork (WO-RP) from a food processing industry was studied as a source of biodiesel. The WO-RP was characterized and was found to have a high acid value of $4.30 \mathrm{mg} \mathrm{KOH} / \mathrm{g}$. A pre-treatment using $\mathrm{H}_{2} \mathrm{SO}_{4}$ was done through the standard titration method that resulted in a reduction of acid value to $0.75 \mathrm{mg} \mathrm{KOH} / \mathrm{g}$. The transesterification process over the $\mathrm{KOH}$ catalyst was carried out and optimized using the central composite design (CCD) using the Design Expert 7.0 software. The optimum conditions were found at 3:1 methanol-oil molar ratio, $0.55 \%$ catalyst loading, and 45 -min reaction time. At optimum conditions, the biodiesel yield was $95.28 \pm 0.15 \%$. Its chemical characteristics were tested in terms of acid value at $0.75 \mathrm{mg} \mathrm{KOH} / \mathrm{g}$, ash content at 0.01 wt $\%$, density at $0.86 \mathrm{~g} / \mathrm{cm}^{3}, \mathrm{HHV}$ at $39.98 \mathrm{MJ} / \mathrm{kg}$, water content at $0.10 \%$, and kinematic viscosity at $6.9 \mathrm{~mm}^{2} / \mathrm{s}$. The FAME profile shows the presence of linoleic, palmitic, oleic and stearic acid as major fatty acid components and functional group shows carbonyl group with traces of carboxylic at $1719 \mathrm{~cm}^{-1}$ and the sharp peak of esters at $1749 \mathrm{~cm}^{-1}$ indicating that the derived product is biodiesel.
\end{abstract}

Keywords: Used oil, Rendered pork oil, Biodiesel, Potassium hydroxide catalyst, Transesterification

\section{Introduction}

The global energy production is a vital link that drives the economy, and $90 \%$ of non-renewable energy sources from fossil fuel (natural gas, petroleum, and coal) and nuclear power plant continuously powers it. However, two emerging problems are associated with the use of fossil-based fuel. One of these is availability. Due to the growing population and industrialization, the energy resources become rapidly depleted, and it takes a long time for it to regenerate over the years. Accordingly, it is estimated that in the year 2040, the world energy demand will rise over 60\% (US Energy Information Administration 2017). The world is not yet ready for this eventuality to write the obituary of fossil fuels, which is forecasted to last only in the next 45 years (Mabayo et al. 2018).

\footnotetext{
*Correspondence: valmabayo@gmail.com

${ }^{1}$ College of Engineering and Technology, University of Science and Technology of Southern Philippines, 9004 Claveria, Philippines Full list of author information is available at the end of the article
}

Second is the environmental concern due to unwanted $\mathrm{CO}_{2}$ emitted after burning fossil-based fuel (Russel 2003). The $\mathrm{CO}_{2}$ is one of the known offenders of global warming, for it contributed as much as $72 \%$ of the greenhouse gases (Kibasi 2018). These greenhouse gases absorb longwave radiation from the earth that results in increasing atmospheric temperature (Shaftel and Jackson 2016). For this reason, scientists worldwide have been searching for alternative sources that are economically viable and environmentally sustainable.

One of these is the production of biodiesel from underutilized raw material. Biodiesel is an environmentally sound alternative source of petrodiesel because of less toxicity, better lubricating properties, renewability, biodegradability, and lesser greenhouse gas emission than fossil diesel fuel (Mansir et al. 2018). These are proven from the previous studies of Bankovic-Ilic et al. (2014), Encinar et al. (2011), Arazo et al. (2016) and Feddern et al. (2011), among others. As to the economic aspect, there have been several studies reported 
as to biodiesel production using low-cost oils such as the study of Pan et al. (2018), Zhang et al. (2018), Ibrahim et al. (2019) and Sun et al. (2019) among others.

However, the technology of bio-based energy is still at an infant stage and is expensive to commercialize. This is significantly affected by the costly raw materials used and the efficiency of the process. At present, biodiesel is blended with petrodiesel fuels in most countries. The United States mandates a $20 \%$ blend, while China requires at least a 10\% blend (Lane 2016). In the Philippines, a $10 \%$ blend is expected to be observed starting the year 2020 (13th Congress of the Philippines 2006).

The challenge nowadays is to produce a biofuel that is technically feasible, economically viable, and environmentally sustainable. One consideration is the use of waste oil from industries and manufacturing entities. This supports the movement of legislators in the Philippines through the proposed "Anti-Used Cooking Oil Act," which prevents the recycling of used cooking oil in the country. Therefore, industries using cooking oil are now in trouble with the disposal of their wastes as not to violate regulatory and statutory requirements. One of these industries is the SLERS Industries, Inc., with waste oil of rendered pork (WO-RP).

This study used the WO-RP from SLERS Industries, Inc. for the production of energy-giving liquidphase fuel called biodiesel. This explores specifically the possibility of producing an alternative fuel for the said company to their LPG-ran burners used in cooking their products from their own generated waste. In the refining process, pre-treatment of waste oil was employed using the esterification process to minimize its acid value. The production of biodiesel from WO-RP is optimized through the transesterification process, considering the effects of methanol-oil ratio, catalyst dosage, and reaction time. The biodiesel product is analyzed by the free fatty acid level, acid value, FAME profile, functional groups, ash content, water content, higher heating value, kinematic viscosity, density, and $\mathrm{pH}$.

\section{Materials and methods}

\section{Preparation of waste oil of rendered pork}

The waste oil of rendered pork (WO-RP) was collected from the SLERS Industries, Inc. in Alae, Bukidnon, Philippines. The waste oil was settled in a separatory funnel for 7 days forming two layers classified as the active oil and inactive oil (composed of residual fats). The active oil was gathered and filtered using filter paper. The filtered oil was washed with hot water several times and was heated under $105 \pm 5{ }^{\circ} \mathrm{C}$ for $60 \mathrm{~min}$ for water content removal.

\section{Characteristics of waste oil of rendered pork}

The properties of WO-RP was determined in terms of fatty acid level at University Agrivironmental Laboratory, $\mathrm{pH}$ value through $\mathrm{pH}$ paper, moisture content using KF titration, functional groups through Fourier Transform Infrared Radiation (FTIR) analysis using Shimadzu FTIR 8400 S at Pilipinas Kao, Jasaan, Misamis Oriental, Philippines, and fatty acid profile through gas chromatography and mass spectroscopy (GC-MS) at F.A.S.T. Laboratory-Cubao, Philippines.

\section{Pre-treatment of WO-RP}

The pre-treatment process was done using a $500-\mathrm{mL}$ round bottom flask Pyrex reactor equipped with a reflux condenser and immersed in the water bath. First, $100 \mathrm{~mL}$ of WO-RP was heated under $60 \pm 5{ }^{\circ} \mathrm{C}$. The process employed $0.5 \%$ and $1 \% \mathrm{H}_{2} \mathrm{SO}_{4}$ variation at 6:1 methanol-oil ratio. Conversion efficiency was observed every 60-min interval of reaction. Each sample was allowed to settle for $180 \mathrm{~min}$ and was purified using deionized water for acid value determination.

\section{Acid value determination}

The acid level was determined through titration analysis in accordance with the method described by Sahar et al. (2018). Titration was carried out using a manual bottle-top burette with LCD (Brand gmbh.co kg). First, a standard amount of indicator solution was prepared by dissolving $1.0 \mathrm{~g}$ of phenolphthalein in a $50 \%$ solution of ethanol and water (50 mL ethanol:50 mL water). Then, the prepared $10 \mathrm{~mL}$ of ethanol was mixed to $0.5 \mathrm{~g}$ of oil sample in an Erlenmeyer flask with two drops of indicator solution. The prepared sample was titrated using $0.1 \mathrm{~mol}$ of $\mathrm{NaOH} / \mathrm{L} \mathrm{H}_{2} \mathrm{O}$ (4 g of $\mathrm{NaOH}$ dissolved in 1- $\mathrm{L}$ distilled water) until the first color change. Triplication of data per sample was done during this process and was calculated using Eq. (1) (Sahar et al. 2018), where FFA is the free fatty acid level (\%), $V$ is the volume of titrant, $N$ is the normality of titrant and $W$ is the weight of the oil sample.

$$
\begin{aligned}
& \mathrm{FFA}=V \times N \times \frac{28.2}{W} \\
& \mathrm{AV}=\mathrm{FFA} \times 1.989
\end{aligned}
$$

\section{Parametric and optimizations studies}

Central composite design (CCD) of the Response Surface Methodology (RSM) was used in this study using the Design Expert 7.0 software. Each run of the experiment was based on the generated combination of CCD in terms of methanol-oil ratio, amount of catalyst, and reaction time. Presented in Table 1 are the range and 
Table 1 Range and level of the variables based on the parametric study

\begin{tabular}{llllll}
\hline Independent variable & \multicolumn{2}{l}{ Coded level } \\
\cline { 2 - 6 } & $\mathbf{- 2}$ & $\mathbf{- 1}$ & $\mathbf{0}$ & $\mathbf{1}$ & $\mathbf{2}$ \\
\hline Methanol-oil ratio (mol) & 2 & 3 & 4 & 5 & 6 \\
Amount of catalyst (wt\%) & 0.25 & 0.50 & 0.75 & 1.00 & 1.25 \\
Reaction time (min) & 30 & 45 & 60 & 75 & 90 \\
\hline
\end{tabular}

level of the variables employed in this study. In determining these range and level, the parametric study principle was employed, which took one variable as constant, while varying the other variables to determine the peak of the graph once the data are plotted (Gumaling et al. 2018).

The values determined in the parametric studies were carried out in the actual experimental runs and optimization studies. These values were considered in the experimental design for the transesterification experiment with the aid of CCD.

\section{Transesterification experiment}

A constant amount of $25-\mathrm{mL}$ pretreated WO-RP was placed in the $500-\mathrm{mL}$ capacity Pyrex reactor immersed in the water bath equipped with a water condenser. The solution was heated under $65 \pm 5{ }^{\circ} \mathrm{C}$ in a hotplate with a magnetic stirrer. The magnetic capsule stirred the mixture vigorously and distributed the heat of the reaction mixture, and the temperature was monitored using a thermometer. The prepared methanol and catalyst were mixed in a beaker and poured slowly into the reactor. In this stage, the triglyceride is converted into methyl esters as manifested by two phases (upper phase-biodiesel, lower phase-glycerol). After that, overnight settling was employed using a decanter to separate the biodiesel product from glycerin and catalyst. Afterward, purification and characterization of biodiesel followed. The scheme of the transesterification process is presented in Fig. 1.

\section{Biodiesel purification and yield}

A two-stage process was employed in the biodiesel purification. The first stage was done through washing in the separatory funnel using distilled water, and the second stage was done by drying through heating at $120{ }^{\circ} \mathrm{C}$ in a hot air oven for 1 day.

The biodiesel yield, by mass, of WO-RP was determined using a digital analytical balance. Equation 3 was used in the calculation, where \%Yield is the percent biodiesel yield (\%), $m_{1}$ is the mass of produced biodiesel, and $m_{2}$ is the mass of the bio-oil sample.

$$
\% \text { Yield }=\frac{m_{1}}{m_{2}} \times 100
$$

\section{Product analysis and characterization}

The biodiesel produced was analyzed and compared to the conventional diesel in terms of acid value, ash content, density, high heating value (HHV), kinematic viscosity, water content, fatty acid methyl ester (FAME) profile, and functional group.

The acid value was determined using titration and computation method, adopting the procedure in the study of Sahar et al. (2018). The ash analysis was done following the ASTM 0482-07 (Standard test method for ash from petroleum products) at F.A.S.T Laboratory-Cubao, Philippines. The density at room temperature was obtained using the standard method using analytical balance (mass) and graduated cylinder (volume). The high heating value was determined using the Bomb Calorimeter Precision Method following the ASTM D4809 (Standard test method for the heat of combustion of liquid hydrocarbon fuels). Water content was determined using Karl Fischer Titration at F.A.S.T Laboratories-Cubao, Philippines. The kinematic viscosity of biodiesel was determined by following the ASTM D-445-71 (Kinematic viscosity of transparent, opaque liquid) at Philippine Sinter Corporation, Villanueva, Misamis Oriental, Philippines. The

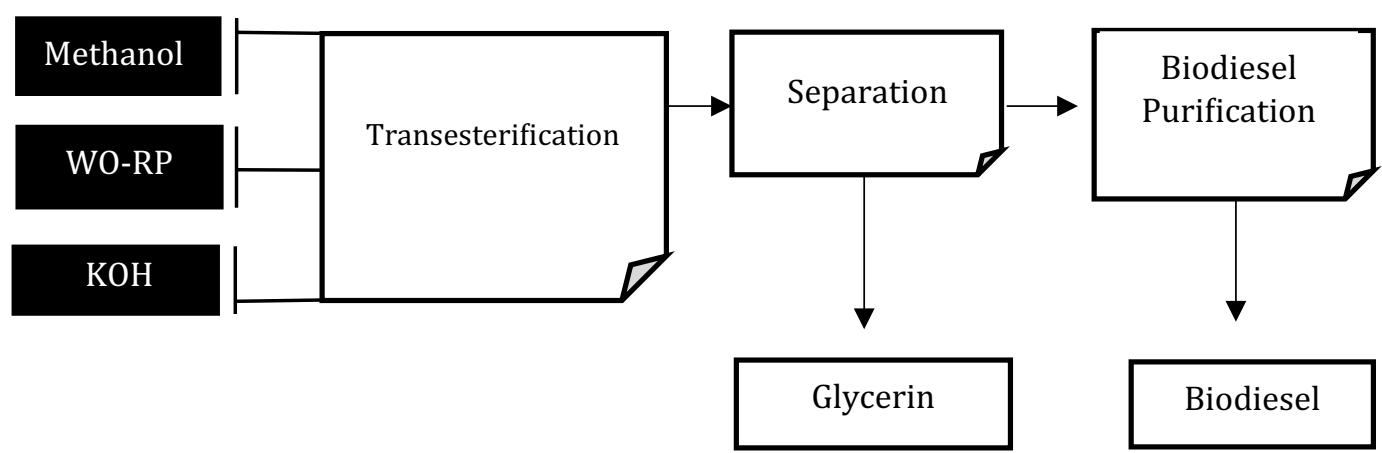

Fig. 1 Schematic flow of the transesterification process 
FAME profile was done using gas chromatography-mass spectrometry following the official method of analysis of AOAC international, 19th ed., 2012 at F.A.S.T Laboratories-Cubao, Philippines, and the functional group analysis was done through Fourier Transform Infrared (FTIR) spectroscopy (Shimadzu FTIR 8400S) at Pilipinas Kao, Incorporated in Jasaan, Misamis Oriental, Philippines.

\section{Results and discussion}

\section{Characterization of waste oil of rendered pork}

The WO-RP was allowed to settle for about 7 days, forming a two-layer phase, mostly active oil (compose of vegetable oil and unsaturated fats) and inactive oil (consist of saturated fat, residual skin, and meat). The active oil was taken and used throughout the conduct of the study. Moisture content is considered as the culprit that hinders the biodiesel reaction processes. In acid esterification, water present tends to dilute sulfuric acid out from the methanol resulting in the unavailability of acid to catalyze the esterification (Diaz-Felix et al. 2009). While in base transesterification, it will react to base catalyst forming saponification reaction. Therefore, moisture content was measured before subjecting to pre-treatment and transesterification. It was found to be $0.14 \%$ after washing WO-RP and heating at $105 \pm 5{ }^{\circ} \mathrm{C}$ for $60 \mathrm{~min}$. This value is low enough from the study of Encinar et al. (2011), which uses $0.3 \%$ moisture content for both acid and base transesterification without any significant effect on the reaction.

The active and inactive oil of WO-RP were characterized (Table 2) according to its acid value and FFA, and this contains $8.55 \mathrm{mg} \mathrm{KOH} / \mathrm{g}(4.30 \mathrm{wt} \%)$ and $9.74 \mathrm{mg} \mathrm{KOH} / \mathrm{g}$ (4.90 wt \%), respectively. This value is lower than the report of Dias et al. (2009) using waste lard with an acid level $14.57 \mathrm{mg} \mathrm{KOH} / \mathrm{g}$ (7.3 wt\%) and higher than the result of Sahar et al. (2018) of waste cooking oil with an acid value $5.5 \mathrm{mg} \mathrm{KOH} / \mathrm{g}$.

The acid value of waste fats is expected to be higher than of vegetable oils (Dias et al. 2009; Banković-Ilić et al. 2014). However, the above result shows a slight difference only of the acid number, which contradicts the ideas of the above observation. This may be because of the blending of vegetable oil with rendered fats that neutralized

Table 2 Characteristics of waste oil of rendered pork

\begin{tabular}{lllc}
\hline Property & Unit & WO-RP & Animal fat \\
\hline Moisture content & $\%$ & 0.14 & 0.13 \\
Acid value & $\mathrm{mg} \mathrm{KOH} / \mathrm{g}$ & $8.55^{\mathrm{a}}, 9.74^{\mathrm{b}}$ & 14.57 \\
Free fatty acid (FFA) & $\%$ & $4.30^{\mathrm{a}}, 4.90^{\mathrm{b}}$ & 4.90 \\
Density @room temperature & $\mathrm{g} / \mathrm{cm}^{3}$ & 0.897 & 0.916
\end{tabular}

\footnotetext{
a Active oil
}

b Inactive oil the acid level of saturated fats. This idea is consistent with the study of Canoira et al. (2008) and Dias et al. (2009) that the blending of vegetable oil will improve the chemical properties of animal fats, including the acid value. However, the above value is still not favorable in base transesterification and requires pre-treatment to lower the acid level below $1 \mathrm{mg} \mathrm{KOH} / \mathrm{g}$ (Abdullah et al. 2013). The density of WO-RP at room temperature was found to be at $0.897 \mathrm{~g} / \mathrm{cm}^{3}$; this value is not far from the study of Sander et al. (2018) that obtained 0.916 using lard.

The functional groups of WO-RP were then analyzed using FTIR spectrometry. Presented in Fig. 2 and Table 3 is the FTIR spectrum and the various peaks under 500 $5000 \mathrm{~cm}^{-1}$ wavenumber. Using the LabCognition irAnalyze software, spectral peaks of alkane $(\mathrm{C}-\mathrm{H}$ stretch) was determined between 2850 and $3000 \mathrm{~cm}^{-1}$ wavelengths with an actual peak at $2909 \mathrm{~cm}^{-1}$.

Aromatic compound $(\mathrm{C}=\mathrm{C}$ stretch) was also identified in the spectra around $1400-1600 \mathrm{~cm}^{-1}$ with actual wavelength at $1498 \mathrm{~cm}^{-1}$. A short peak of ether was in the range of $1000-1300 \mathrm{~cm}^{-1}$ with actual value 1089 and $1039 \mathrm{~cm}^{-1}$. A presence of carbonyl was also observed in the spectrum with actual value at $1689 \mathrm{~cm}^{-1}$ which is within the range of $1670-1820 \mathrm{~cm}^{-1}$. This value also signifies the presence of carbonyl compound group

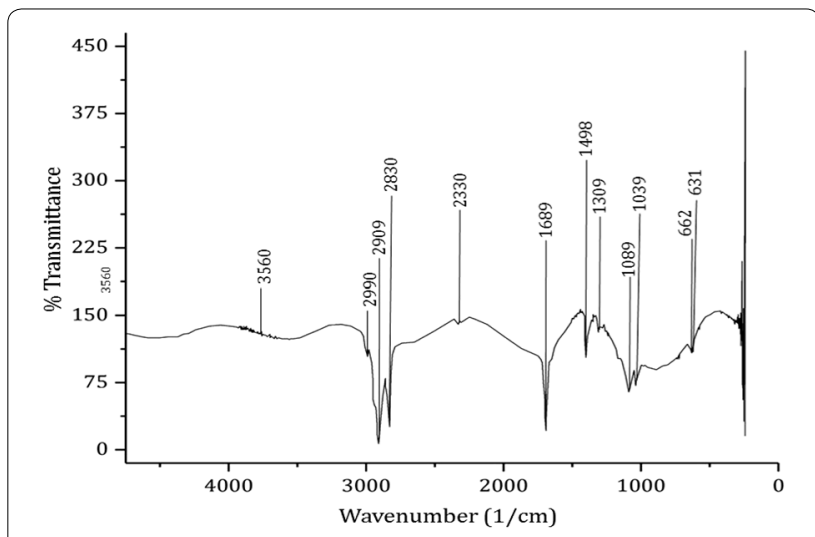

Fig. 2 Fourier Transform Infrared Radiation (FTIR) spectrum of WO-RP

Table 3 The main peak of the FTIR spectrum of WO-RP and their assignments

\begin{tabular}{lll}
\hline Assignment & \multicolumn{2}{l}{ Wavelength peak, cm } \\
\cline { 2 - 3 } & Range & Actual \\
\hline C-H stretch (alkane) & $2850-3000$ & 2990,2909 \\
C=H stretch (carbonyl) & $1670-1820$ & 1689 \\
C=C-C stretch (aryl) & $1400-1600$ & 1498 \\
C-O stretch (ether) & $1000-1300$ & 1089,1039 \\
C-H send (alkyne) & $610-680$ & 631,662 \\
\hline
\end{tabular}


Table 4 Fatty acid composition of waste oil of rendered pork

\begin{tabular}{llll}
\hline Fatty acid profile & Molecular formula & Relative wt\% & MW (g/mol) \\
\hline Capric acid & C10:0 & 0.11 & 172.268 \\
Lauric acid & C12:0 & 0.14 & 200.3178 \\
Myristic acid & C14:0 & 1.51 & 228.3709 \\
Palmitic acid & C16:0 & 23.90 & 256.4 \\
Palmitoleic acid & C16:1 & 2.91 & 254.414 \\
Heptadecanoic acid & C17:0 & 0.21 & 270.45 \\
cis-10-heptadeca- & C17:1 & 0.28 & 268.441 \\
noic & & & \\
Stearic acid & $\mathrm{C} 18: 0$ & 9.40 & 284.48 \\
Oleic acid & $\mathrm{C} 18: 1 \mathrm{n} 9 \mathrm{C}$ & 46.70 & 282.47 \\
Linolenic acid & $\mathrm{C} 18: 2 \mathrm{n6C}$ & 13.30 & 278.436 \\
y-linolenic acid & $\mathrm{C} 18: 3 \mathrm{n6}$ & 0.47 & 278.436 \\
Other & & 1.07 & \\
\hline
\end{tabular}

of aldehydes and ketones ranging between 1650 and $1750 \mathrm{~cm}^{-1}$ which are important indicators of good oil quality in the biodiesel refinery (Arazo et al. 2016).

The major fatty acid contents, as shown in Table 4, were $46.70 \%$ oleic acid, $23.90 \%$ palmitic acid, and $13.30 \%$ linolenic acid. These values are higher than the results in the study of Dias et al. (2009) in terms of linolenic using pork lard as well as to the result reported by Encinar et al. (2011) in terms of both oleic and linolenic acids. The fatty acid content of the feedstock is a good indicator of biodiesel viscosity and density because fatty acid is a long chain of carbon. The increasing value of fatty acid means an increasing level of viscosity (Refaat 2009; Encinar et al. 2011), indicating the unsuitability of oil in the direct transesterification reaction.

\section{Pre-treatment result}

The pre-treatment of WO-RP was done following the optimum conditions reported in the study of Chai et al. (2014) using sulfuric acid $\left(\mathrm{H}_{2} \mathrm{SO}_{4}\right)$. Catalyst loading was varied $(0.5 \%$ and $1 \%)$ to compare the conversion rate of acid value at a different time interval. Presented in Fig. 3 is the effectivity of the two different catalyst loadings.

A rapid decrease in the first 60 min was observed, but the data tended to be steady with a slight difference in acid level in the next time interval. This behavior is inclined to the previous studies where the formation of water tended to dilute acid catalyst out from the methanol resulting in the unavailability of acid to catalyze the reaction (Dias et al. 2009; Encinar et al. 2011; Banković-Ilić et al. 2014).

The optimum conversion rate was observed at $0.75 \mathrm{mg} \mathrm{KOH} / \mathrm{g}$ acid value using a $0.5 \%$ catalyst loading in $180 \mathrm{~min}$. A slight difference can be observed using 120 -min reaction at $0.79 \mathrm{mg} \mathrm{KOH} / \mathrm{g}$ acid level using the

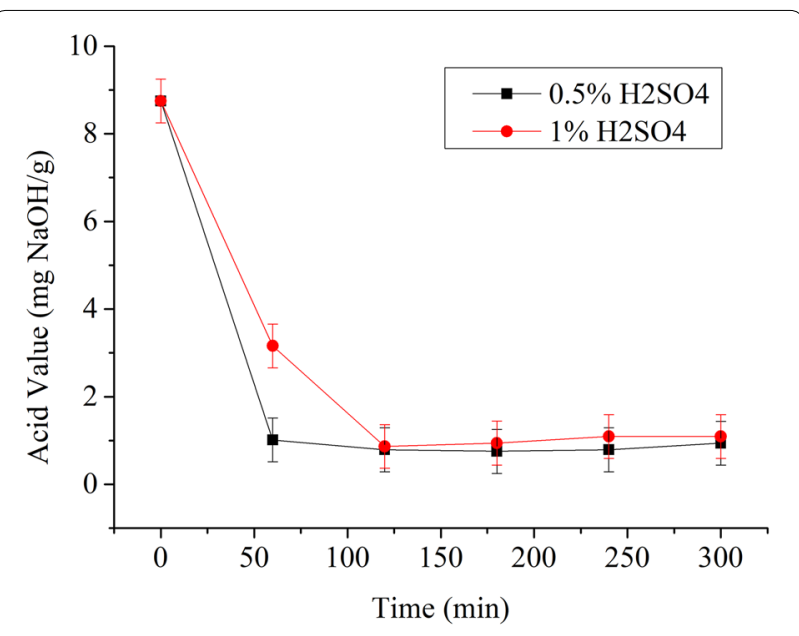

Fig. 3 Effect of reaction time on acid value

same loading (Chai et al. 2014). After choosing the best pre-treatment condition, transesterification of the esterified oil using the condition of (Sahar et al. 2018) of 6:1 methanol-oil ratio, $1 \%$ catalyst load for 60 min was carried out. A higher acid value than the standard acid value of $0.80 \mathrm{mg} \mathrm{KOH} / \mathrm{g}$ for biodiesel according to the ASTM D6751-02, 2002 was obtained in the 120-min treatment; thus, 180-min treatment was used throughout the conduct of the study. This condition is not far from the industrial practices of pre-treatment using 6:1 methanoloil ratio, $65^{\circ} \mathrm{C}$, and $120 \mathrm{~min}$ (Chai et al. 2014).

\section{Parametric study analysis}

Figure 4 presents the results of the parametric study conducted. The first part was studied by varying methanol-oil ratio at five levels with catalyst load at $1 \%$, and the reaction time at $60 \mathrm{~min}$. The recorded yield is presented in Fig. 4a, which shows the optimum peak of methanol-oil ratio at run 4 , with the actual yield at $92.6 \%$. A decrease of yield was observed after increasing amount of methanol. Therefore, 4:1 methanol-oil ratio was selected and held constant at 0 level in the next part of the parametric study.

On the next stage, catalyst load was varied around $0.25-1.50 \%$ while taking methanol-oil ratio and reaction time as constant. The catalyst loading of $0.75 \%$ was found to be the most efficient level as could be seen in Fig. 4b, so it was taken as constant in the next stage of the parametric study varying reaction time to complete the exact range and levels of all variables. The peak values of catalyst loading (0.75\%) and methanol-oil ratio (4:1) were held constant and the time was varied from 30 to $90 \mathrm{~min}$.

It could be observed that, at $60 \mathrm{~min}$, the highest biodiesel yield was recorded (Fig. 4c). In general, the 

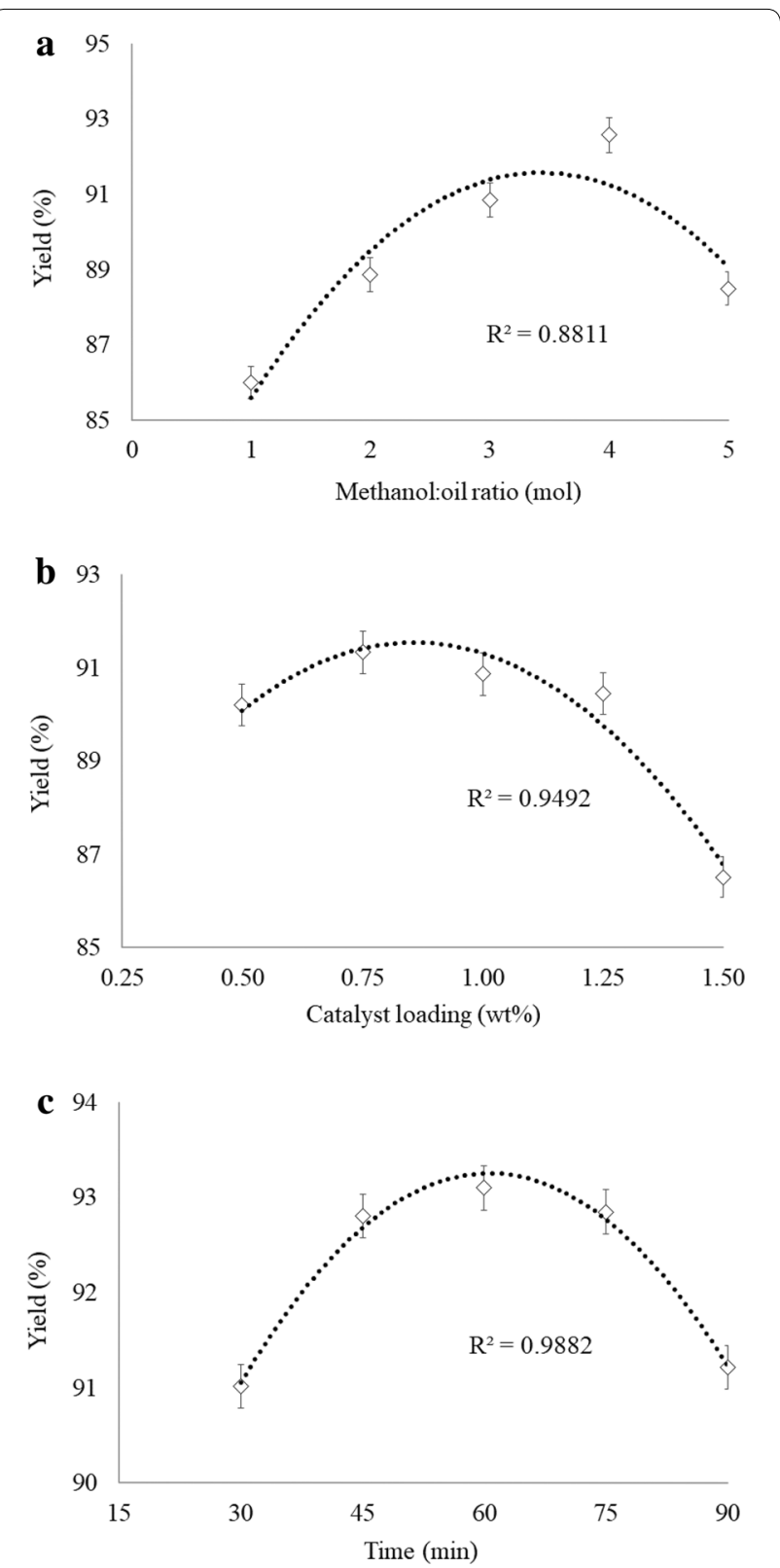

Fig. 4 Biodiesel yield at varied $\mathbf{a}$ methanol-oil ratio, $\mathbf{b}$ catalyst loading, and c time

parametric results of the three variables were found to be at $4: 1$ methanol-oil ratio, $0.75 \%$, catalyst loading, and 60-min reaction time. This condition was then considered as the center point in the response surface optimization of biodiesel yield from the waste oil of rendered pork.

\section{Response surface analysis of WO-RP}

Table 5 presents the response values using central composite design $(\mathrm{CCD})$ as the experimental design. The
Table 5 Experimental design matrix and the resulting yield

\begin{tabular}{lllll}
\hline Run & $\begin{array}{l}\text { Methanol/oil } \\
\text { ratio (mol) }\end{array}$ & $\begin{array}{l}\text { Catalyst load } \\
\text { (wt\%) }\end{array}$ & $\begin{array}{l}\text { Reaction } \\
\text { time }(\mathbf{m i n})\end{array}$ & Yield (\%) \\
\hline 1 & 4 & 0.75 & 60 & 94.48 \\
2 & 4 & 0.75 & 60 & 92.37 \\
3 & 5 & 0.55 & 45 & 91.88 \\
4 & 3 & 0.55 & 45 & 95.52 \\
5 & 4 & 0.75 & 60 & 93.13 \\
6 & 4 & 0.75 & 60 & 93.68 \\
7 & 4 & 0.75 & 60 & 94.47 \\
8 & 5 & 0.95 & 75 & 88.74 \\
9 & 5 & 0.55 & 75 & 94.64 \\
10 & 6 & 0.75 & 60 & 88.26 \\
11 & 2 & 0.75 & 60 & 93.97 \\
12 & 3 & 0.95 & 45 & 93.41 \\
13 & 5 & 0.95 & 45 & 88.78 \\
14 & 3 & 0.95 & 75 & 89.12 \\
15 & 4 & 1.15 & 60 & 87.23 \\
16 & 4 & 0.75 & 30 & 93.74 \\
17 & 4 & 0.35 & 60 & 96.17 \\
18 & 4 & 0.75 & 60 & 93.92 \\
19 & 3 & 0.55 & 75 & 95.27 \\
20 & 4 & 0.75 & 90 & 92.69 \\
\hline
\end{tabular}

design was generated to evaluate and optimize the process variables of methanol-oil molar ratio, catalyst loading, and reaction time. The response measure WO-RP biodiesel yield varies from $87.23 \%$ (run 15) to $96.17 \%$ (run 17). The highest yield of $96.17 \%$ is higher compared to the yield in the study of Ezekannagha et al. (2017), which signifies that the biodiesel yield from WO-RP can still be maximized through the aid of response surface optimization.

\section{Model fitting of WO-RP}

The analysis of variance (ANOVA) of the response surface-reduced quadratic model for the percentage of oil yield from WO-RP was carried out and presented in Table 6 . The model $p$-value of $<0.0001$ implies that the generated model is significant. This means that there is only a $<0.01 \%$ chance that error could occur due to the unexpected data variation due to the interaction of the operating variables.

The lack of fit $p$-value of 0.9327 implies that the lack of fit is not significant relative to the pure error. The analysis fit summary suggested that the response surface-reduced quadratic model best fitted the results in predicting the biodiesel yield from WO-RP. A high coefficient of determination $\left(R^{2}\right)$ value of 0.9657 means that the model is robust in predicting the biodiesel yield. This also implies that there is $96.57 \%$ 
Table 6 ANOVA of the reduced quadratic model of oil yield from WO-RP

\begin{tabular}{|c|c|c|c|c|c|}
\hline Source & Sum of squares & $d f$ & Mean square & $F$ value & $\begin{array}{l}p \text {-value } \\
\text { Prob }>F\end{array}$ \\
\hline Model & 131.77 & 7 & 18.82 & 48.23 & $<0.0001^{\mathrm{a}}$ \\
\hline A-methanol-oil ratio & 26.78 & 1 & 26.78 & 68.62 & $<0.0001^{\mathrm{a}}$ \\
\hline B-catalyst loading & 77.18 & 1 & 77.18 & 197.75 & $<0.0001^{a}$ \\
\hline C-reaction time & 0.96 & 1 & 0.96 & 2.46 & $0.1427^{b}$ \\
\hline$A C$ & 6.59 & 1 & 6.59 & 16.88 & $0.0014^{\mathrm{a}}$ \\
\hline$B C$ & 5.85 & 1 & 5.85 & 14.98 & $0.0022^{\mathrm{a}}$ \\
\hline$A^{2}$ & 10.58 & 1 & 10.58 & 27.11 & $0.0002^{\mathrm{a}}$ \\
\hline$B^{2}$ & 6.26 & 1 & 6.26 & 16.04 & $0.0017^{a}$ \\
\hline Residual & 4.68 & 12 & 0.39 & & \\
\hline Lack of fit & 1.34 & 7 & 0.19 & 0.29 & $0.9327^{b}$ \\
\hline$R^{2}=0.9657$ & & & & & \\
\hline
\end{tabular}

a Significant

b Not significant

certainty that the generated model can explain the variability of data. Equation 4 shows the reduced quadratic model equation based on actual factors, where $A$ represents methanol:oil ratio, $B$ represents catalyst loading, and $C$ represents reaction time.

$$
\begin{aligned}
\text { Yield }(\%)= & 92.56+0.15 A+24.40 B-0.045 C \\
& +0.06 A C-0.29 B C-0.63 A^{2}-12.19 B^{2}
\end{aligned}
$$

It could be observed in the model equation that terms $A B$ and $C^{2}$ were neglected because of their high $p$-value, which means that they are not significant terms. The regression analysis showed that $A$ is a significant term $(p$-value $<0.0001)$, which means that methanol-oil ratio is an essential factor in the study. This could be justified by the coefficient of $A$ in the established model equation, which is positive, denoting that increasing $A$ means increasing yield. The same happens with the increase of $B$ since catalyst loading is also considered significant with $p$-value $<0.0001$.

On the other hand, the reaction time is found to be not significant ( $p$-value 0.1427 ), which is once again justified by the generated model equation where the numerical coefficient of $C$ is negative, which implies that increase in its value could result in a decrease in the biodiesel yield. The interaction of the variables and their quadratic effects can also be seen in the equation where positive coefficients mean the interaction positively affects the yield, and negative coefficients mean otherwise. Using the CCD generated model equation, the results of the actual run were validated, as shown in Table 7.

It can be observed in the table that the actual and predicted responses are close to each other, which justifies the reliability of the data gathered.
Table 7 Actual vs. predicted oil yield from WO-RP

\begin{tabular}{llllll}
\hline $\begin{array}{l}\text { Run } \\
\end{array}$ & $\begin{array}{l}\text { Methanol/ } \\
\text { oil ratio } \\
\text { (mol) }\end{array}$ & $\begin{array}{l}\text { Catalyst } \\
\text { load } \\
\text { (wt\%) }\end{array}$ & $\begin{array}{l}\text { Reaction } \\
\text { time } \\
\text { (min) }\end{array}$ & $\begin{array}{l}\text { Actual yield } \\
(\%)\end{array}$ & $\begin{array}{l}\text { Predicted } \\
\text { yield (\%) }\end{array}$ \\
\hline 1 & 4 & 0.75 & 60 & 94.48 & 93.47 \\
2 & 4 & 0.75 & 60 & 92.37 & 93.47 \\
3 & 5 & 0.55 & 45 & 91.88 & 91.73 \\
4 & 3 & 0.55 & 45 & 95.52 & 96.14 \\
5 & 4 & 0.75 & 60 & 93.13 & 93.47 \\
6 & 4 & 0.75 & 60 & 93.68 & 93.47 \\
7 & 4 & 0.75 & 60 & 94.47 & 93.47 \\
8 & 5 & 0.95 & 75 & 88.74 & 88.67 \\
9 & 5 & 0.55 & 75 & 94.64 & 94.77 \\
10 & 6 & 0.75 & 60 & 88.26 & 88.35 \\
11 & 2 & 0.75 & 60 & 93.97 & 93.52 \\
12 & 3 & 0.95 & 45 & 93.41 & 93.45 \\
13 & 5 & 0.95 & 45 & 88.78 & 89.05 \\
14 & 3 & 0.95 & 75 & 89.12 & 89.44 \\
15 & 4 & 1.15 & 60 & 87.23 & 87.13 \\
16 & 4 & 0.75 & 30 & 93.74 & 93.96 \\
17 & 4 & 0.35 & 60 & 96.17 & 95.91 \\
18 & 4 & 0.75 & 60 & 93.92 & 93.47 \\
19 & 3 & 0.55 & 75 & 95.27 & 95.54 \\
20 & 4 & 0.75 & 90 & 92.69 & 92.98 \\
\hline & & & & &
\end{tabular}

Effect of operating variables to the biodiesel yield

Figures 5 and 6 show the 3D plots showing the effects of variables in biodiesel yield. The amount of methanol/ oil ratio, catalyst loading, and reaction in the transesterification process is significant (Sahar et al. 2018).

As illustrated in Fig. 5, increasing reaction time showed opposite results concerning to methanol-oil ratio. At low methanol-oil ratio, increasing time results in decreasing 


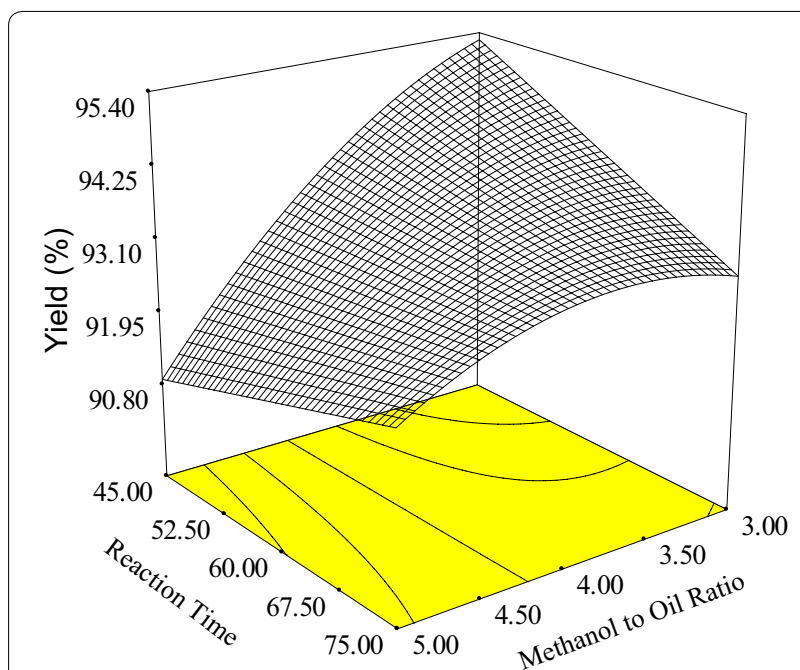

Fig. 5 3D plot of the effects of methanol-oil ratio and time to FAME yield

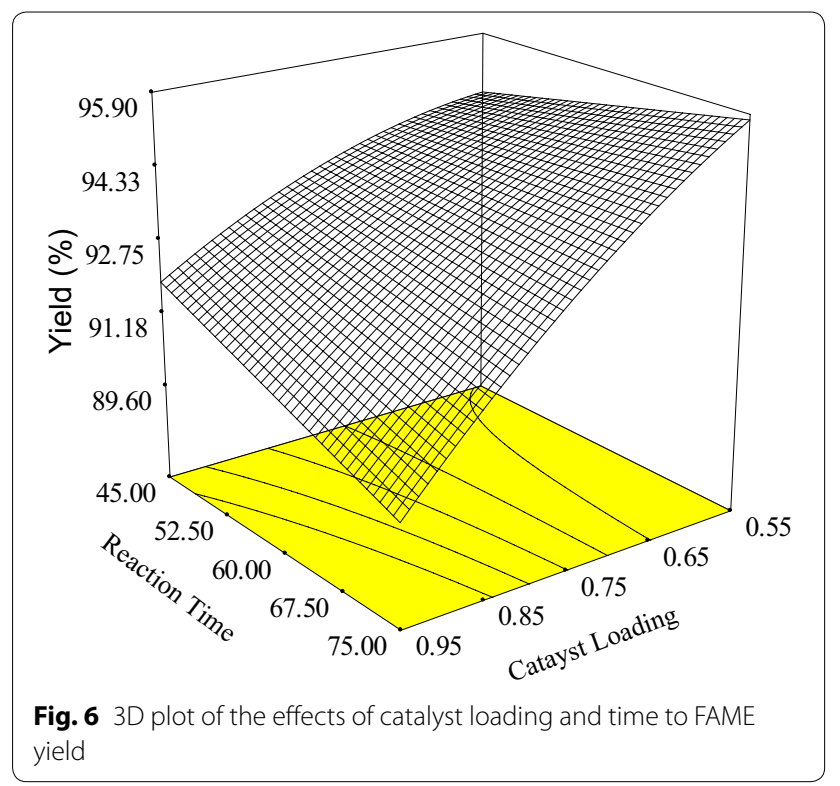

biodiesel yield. On the other hand, at high methanol-oil ratio, increasing time showed increased biodiesel yield. This inconsistency in the variable reaction time is consistent with the result in the ANOVA that reaction time is not significant while methanol-oil ratio is significant, showing the same trend of biodiesel yield regardless of the reaction time. Also, as reflected in Fig. 5, an increase in the methanol-oil ratio corresponds to a decreasing trend in the yield. This is similarly observed in the study of Sahar et al. (2018). As explained, higher methanoloil ratio affects the solubility of glycerin which causes a decrease of the FAME yield.
Meanwhile, the interaction effect of catalyst loading and reaction time is shown in Fig. 6. The same observation can be interpreted that reaction time is not significant because of the inconsistency of the effects of reaction time to the biodiesel yield. At low catalyst loading, the biodiesel yield increases as the reaction time increases. However, at high catalyst loading, the biodiesel yield decreases as the reaction time decreases. This as well supports the ANOVA result that reaction time is not significant, and catalyst loading is significant considering a similar trend of biodiesel yield regardless of time. It is also noticeable that the increase in the catalyst load decreases the FAME yield. It is reported by Sahar et al. (2018) that higher catalyst dose favors the soap formation in the reaction mixture which decreases the FAME yield.

\section{Numerical optimization of the biodiesel yield}

Numerical optimization was carried out following the conditions with the highest desirability suggested by the CCD. The chosen solution was carried out in the optimization study and verified with the actual runs. Three verification runs were conducted, and the mean plus the standard deviation was recorded.

The result of the actual runs was compared to the CCD theoretical yield, as summarized in Table 8. The percent error of $0.89 \%$ is below the $5 \%$ acceptable error. This result supported the claim that the response surfacereduced quadratic model used is valid.

\section{Characterization of biodiesel produced from WO-RP}

The biodiesel product was characterized according to the most important properties of the biodiesel. This includes free fatty acid level, acid value, and density. Presented in Table 9 are the properties of the derived biodiesel, which were also compared to ASTM and EN standards.

The acid number of the biodiesel was found to be at $0.75 \mathrm{mg} \mathrm{KOH} / \mathrm{g}$, which is higher than the result of Sahar et al. (2018) with the acid value of $0.6 \mathrm{mg} \mathrm{KOH} / \mathrm{g}$. This result is in agreement with their observation that the use of hot distilled water during purification can significantly affect the acid value of biodiesel. However, the above

\section{Table 8 Optimization and validation of biodiesel yield}

\begin{tabular}{lllll}
\hline Experiment & \multicolumn{2}{l}{ Operating variable } & $\begin{array}{l}\text { Response } \\
\text { yield (\%) }\end{array}$ \\
\cline { 2 - 4 } & $\begin{array}{l}\text { Methanol:oil } \\
\text { ratio (mol.) }\end{array}$ & $\begin{array}{l}\text { Catalyst } \\
\text { loading } \\
\text { (\%) }\end{array}$ & $\begin{array}{l}\text { Reaction } \\
\text { time (min) }\end{array}$ & \\
\hline $\mathrm{CCD}_{\text {(theoretical) }}$ & 3 & 0.55 & 45 & 96.14 \\
Validation $_{\text {(actual) }}$ & 3 & 0.55 & 45 & $95.28 \pm 0.15$
\end{tabular}

Optimization criteria: minimize methanol-oil ratio, catalyst loading, reaction time; maximize FAME yield 
Table 9 Characteristic of biodiesel compared to ASTM and EN standards

\begin{tabular}{lclll}
\hline Property & Biodiesel from WO-RP & ASTM D6751-12 & EN 14214:2012 & Unit \\
\hline Acid number & 0.75 & $<0.8$ & $0.80 \mathrm{max}$ & $\mathrm{mg} \mathrm{KOH} / \mathrm{g}$ \\
Ash content & 0.01 & 0.02 & 0.02 & $\mathrm{~m} \mathrm{mass}$ \\
Density @room temperature & 0.86 & 0.73 & $0.860-0.900$ & $\mathrm{~g} / \mathrm{cm}^{3}$ \\
High heating value & 39.98 & $>35$ & $35-40$ & $\mathrm{MJ} / \mathrm{kg}$ \\
Kinematic viscosity @40 ${ }^{\circ} \mathrm{C}$ & 6.9 & $1.9-6.0$ & $3.5-5.0$ & $\mathrm{~mm} / \mathrm{s}$ \\
Water content & 0.10 & 0.05 & - & $\%$ \\
\hline
\end{tabular}

results are still on the range of acid value standard stipulated in ASTM D6751-12 for biodiesel.

The recorded ash content of biodiesel was $0.01 \%$ which passes the maximum required ash content for biodiesel. This result is similar to the study of Sander et al. (2018) obtaining a value of $0.01 \%$ and lower from the study of Shalaby and El-gendy (2012) and Yesilyurt (2019) obtaining a value of $0.02 \%$ and $0.019 \%$, respectively. Aside from effective distilled washing, inorganic contaminants such as insoluble solids remain from biodiesel were also removed with glycerin during 24-h settling, showing the advantageous effect of having the by-product in the reaction (Al-Hamamre and Yamin 2014). Ash content is an indication of inorganic contaminants that are present to the oil or biodiesel. These inorganic compounds quickly oxidize during the combustion process resulting in ash formation, which is gradually deposited in the engine and decreases performance efficiency (Hagenow et al. 2010; Ap et al. 2011). This result means that the ash content of the biodiesel produced in this study is low enough not to cause such problems above.

It can be observed that the density of WO-RP rapidly decreases after being converted into biodiesel obtaining a value of $0.86 \mathrm{~g} / \mathrm{cm}^{3}$ from $0.89 \mathrm{~g} / \mathrm{cm}^{3}$. This can be a good indication that the triglycerides are effectively converted into methyl esters. In comparison, this value is lower than the result of Sahar et al. (2018) obtaining $0.87 \mathrm{~g} /$ $\mathrm{cm}^{3}$, and way higher than the results of Abdullah et al. (2013) having $0.82 \mathrm{~g} / \mathrm{cm}^{3}$; both of them used waste cooking oil in producing biodiesel. This property is said to be an influencing factor that acts as fuel mass that measures the ability of the fuel to reach the combustion chamber (Barabas and Todoru 2011). The result of this study indicates that the biodiesel produced will not affect the injection efficiency of the engine during the combustion process supported that it passes to the density required for biodiesel stipulated in ASTM and EN standards.

The high heating value (HHV) of biodiesel was found to be $39.98 \mathrm{MJ} / \mathrm{kg}$. This value is higher than the results of Sahar et al. (2018), Al-Hamamre and Yamin (2014) and Yesilyurt (2019), obtaining a value of $37.2 \mathrm{~kJ} / \mathrm{g}, 35.66 \mathrm{MJ} /$ $\mathrm{kg}$ and $37.11 \mathrm{MJ} / \mathrm{kg}$, respectively. However, this is slightly lower than petroleum-based diesel at $41.2 \mathrm{MJ} / \mathrm{kg}$ but still, pass to the minimum required of heating value for fuel at 35-40 MJ/kg (Barabas and Todoru 2011). It can be observed that there is only a small difference in the heating value of WO-RP and the produced biodiesel. It is similar to the previous observation of Issariyakul et al. (2007) and Enweremadu and Mbarawa (2009) that the heating value of methyl esters is not much different from their parent oil. In general, this value means that the produced biodiesel holds enough amount of heat energy that could run a diesel engine by converting heat energy into a mechanical form of energy (Ashraful et al. 2014).

The high viscosity of vegetable oil and rendered animal fats is one of the major reasons that make this oil unsuitable for direct use in a diesel engine. The viscosity of fuel must be indefinite, to avoid engine problems such as poor atomization during injection in the combustion chamber (Kumar and Ali 2010) and the formation of engine deposits (Knothe and Steidley 2005). From its viscous property, it can be observed that the biodiesel viscosity improved up to $6.9 \mathrm{~mm}^{2} / \mathrm{s}$. This is in line with the previous report (Lam et al. 2010; Macedo et al. 2013; Verma et al. 2016) that the transesterification process can significantly improve the chemical properties of bio-oil, including its viscosity. It is slightly higher to the maximum number required for biodiesel from both ASTM and EN standards. However, in some countries like Egypt, this result is still in the range of acceptable value of kinematic viscosity for diesel engine fuel (Shalaby and El-gendy 2012).

Water content removal was done according to the methods described by Abdullah et al. (2013) wherein they gain $0.02 \%$ water content of biodiesel after oven drying for $24 \mathrm{~h}$ at $120^{\circ} \mathrm{C}$. It can be observed that the water content of biodiesel is at $0.10 \%$ which is opposite value of water level. This usually happens when the biodiesel is stored for a longer time before subjecting to water content analysis. Supported that the biodiesel is much more hygroscopic than petrodiesel (Prankl et al. 2004; Barabas and Todoru 2011; Fregolente et al. 2012), it will attract water during higher temperature and precipitated (as free water) after lowering the temperature. This process may repeat and lead to the accumulation of water in biodiesel. 
Also, the study of Fregolente et al. (2012) synthesized the water absorbance of biodiesel and blended biodiesel-diesel fuel. They reported that even at a constant humidity, biodiesel absorbs moisture 6.5 times higher than petroleum diesel fuel. They observed that this hydrophilicity of biodiesel is due to its ester bonds presence, which gives high absorption capacity in moisture. These ideas suited to the result of this study, which suggests the need for proper containment of biodiesel to maintain its acceptable water content level.

The fatty acid methyl ester profile of the resulted biodiesel was done to confirm that the produced product is possessing major acid found in the biodiesel. Also, it is necessary to determine the amount of these fatty acids from biodiesel because these indicate how good is the performance efficiency of the fuel as the relative amounts of these correspond to some advantages and disadvantages. Presented in Fig. 7 is the chromatogram of GCMS analysis of biodiesel from WO-RP.

As shown in Fig. 7, four significant peaks of fatty acid were found to be identified as the sharp peak of oleic acid (C16:1n9c), palmitic acid (C16:0), linoleic acid (C18:2n6c) and followed by a medium peak of stearic acid (C18:0). This result is also found from the study of Sahar et al. (2018), Sander et al. (2018) and Dias et al. (2009), which claims as major acid components that identify biodiesel. For better illustration, summarized in Table 10 are the fatty acids of biodiesel with their relative percentage.

The results show the presence of two different acids. First is saturated fatty acid (lauric, myristic, palmitic, and stearic). Second is unsaturated fatty acid which is composed of two distinct acids, monounsaturated (oleic, palmitoleic, cis-10-heptadecanoic, and cis11-eicosenoic) and polyunsaturated (linoleic acid and cis-11-14-eicosadienoic). From the recent publication of Gumaling et al. (2018), the presence of palmitic and stearic acid at considerable quantities signifies low iodine value, which means the biodiesel is stable at

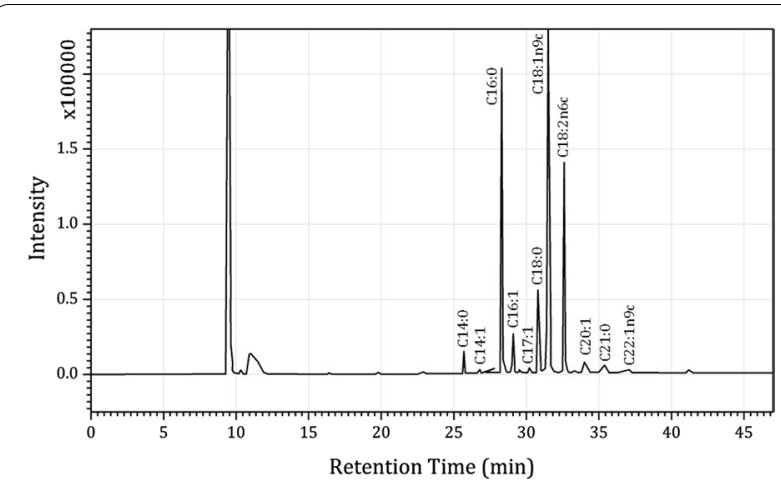

Fig. 7 Chromatogram of GC-MS of biodiesel from WO-RP
Table 10 Fatty acid methyl ester profile of biodiesel from WO-RP

\begin{tabular}{llc}
\hline $\begin{array}{l}\text { Fatty acid profile as methyl } \\
\text { esters }\end{array}$ & Molecular formula & Relative wt\% \\
\hline Saturated & C12:0 & $\Sigma 32.4$ \\
Lauric acid & $\mathrm{C} 14: 0$ & 0.10 \\
Myristic acid & $\mathrm{C} 16: 0$ & 1.33 \\
Palmitic acid & $\mathrm{C} 18: 0$ & 22.3 \\
Stearic acid & & 8.31 \\
Other & & 0.42 \\
Monounsaturated & $\mathrm{C} 18: 1 \mathrm{n} 9 \mathrm{C}$ & $\Sigma 52$ \\
Oleic acid & $\mathrm{C} 16: 1$ & 49.1 \\
Palmitoleic acid & $\mathrm{C} 17: 1$ & 1.84 \\
cis-10-heptadecanoic & $\mathrm{C} 20: 1$ & 0.32 \\
cis-11-eicosenoic & & 0.52 \\
Other & & 0.22 \\
Polyunsaturated & $\mathrm{C} 18: 2 \mathrm{n} 6 \mathrm{c}$ & 14.5 \\
Linoleic acid & $\mathrm{C} 20: 2$ & 0.60 \\
cis-11-14-eicosadienoic & & 15.9 \\
\hline
\end{tabular}

room temperature. As shown in Table 10, a substantial amount of palmitic acid at $22.3 \%$ and stearic acid at $8.31 \%$ was obtained. Therefore, a considerable concentration of this acid in biodiesel indicates good biodiesel storability which is necessary for more extended storage of fuel before use.

The results also show the total percentage of saturated acids at 32.4 which is higher than the results of Al-Hamamre and Yamin (2014). As previous studies presented, an increasing number of saturated fatty acids means increasing the thermal and oxidative stability of fuel, giving the excellent advantage of fuel to store for a longer time, particularly in high-temperature environments (Refaat 2009; Shalaby and El-gendy 2012; Lin and Lin 2012). Therefore, the substantial amount of these acids in the biodiesel indicates good storability which is necessary during transport and containment of fuel. Also, the increase of saturated acid shows higher pour point and cloud point of fuel indication of good biodiesel quality as engine fuel (Kumar et al. 2016).

The spectral peak of the functional group that corresponds compounds can be a good indication that the produced product is possessing components of biodiesel (Shalaby and El-gendy 2012; Meena Devi et al. 2015; Mabayo et al. 2018). Therefore, FTIR spectrometry is done to determine the group of compounds present in biodiesel. This is presented in Fig. 8 ranging $500-5000 \mathrm{~cm}^{-1}$ wavenumber.

It could be observed that the FTIR spectrum of WO-RP dramatically changed after it is converted into biodiesel. This indicates that the transesterification 


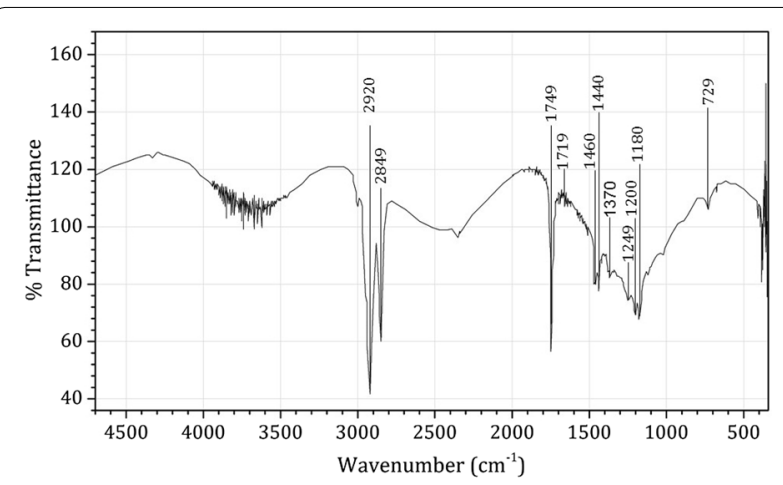

Fig. 8 Fourier Transform Infrared Radiation (FTIR) spectrum of biodiesel

Table 11 Main peak of the FTIR spectrum of biodiesel and their assignment

\begin{tabular}{lll}
\hline Assignment & Wavelength peak, $\mathbf{c m}^{\mathbf{- 1}}$ \\
\cline { 2 - 3 } & Range & Actual \\
\hline $\mathrm{C}-\mathrm{H}$ stretch (alkyl) & $2915-2935 ; 2845-2865$ & $2920 ; 2849$ \\
$\mathrm{C}-\mathrm{O}$ stretch (ester) & $1725-1750$ & 1749 \\
$\mathrm{C}=\mathrm{H}$ stretch (carboxylic acid) & $1700-1725$ & 1719 \\
$\mathrm{C}-\mathrm{H}$ bend $\left(\mathrm{CH}_{2} / \mathrm{CH}_{3}\right)$ & $1425-1465$ & 1460,1440 \\
$\mathrm{C}-\mathrm{H}$ bend $\left(\mathrm{CH}_{3}\right)$ & $1370-1380$ & 1370 \\
Aryl-O stretch (aromatic ethers) & $1230-1270$ & 1249 \\
X-O group ( $\left.\mathrm{SO}_{2}\right)$ & $1180-1200$ & 1200,1180 \\
$\mathrm{C}-\mathrm{H}$ out of plane bend (aryl) & $670-900$ & 729 \\
\hline
\end{tabular}

process significantly transforms WO-RP into biodiesel. However, the existence of a few peaks was obtained due to similarities that are found between triglycerides and methyl esters (Ezekannagha et al. 2017). Using ir-analyze, the main compounds of biodiesel were determined and summarized in Table 11.

The result shows the presence of a carbonyl group with short $\mathrm{C}=\mathrm{H}$ vibration of carboxylic acid around $1700-$ $1725 \mathrm{~cm}^{-1}$. Also, a sharp peak of esters were found at wavenumber at around $1725-1750 \mathrm{~cm}^{-1}$ (Coates 2000). This compound was not found before WO-RP was subjected to transesterification, but then, traces of carboxylic at $1719 \mathrm{~cm}^{-1}$ and strong peak of esters at $1749 \mathrm{~cm}^{-1}$ occurred after the refining process justifying that the product derived has components of biodiesel (Arazo et al. 2016; Mabayo et al. 2018; Gumaling et al. 2018). However, sulfates containing hetero-xy compounds was observed around $1180-1200 \mathrm{~cm}^{-1}$ with X-O group vibration suggesting further purification of biodiesel to remove or eliminate these compounds, which might cause sulfates emission (Feddern et al. 2011).
In general, the biodiesel produced from WO-RP is proven to be a potential source of biodiesel in the country, considering its comparable properties from previous studies of Sahar et al. (2018), Dias et al. (2009) and Abdullah et al. (2013) including petroleum diesel fuel.

\section{Conclusions}

The results of this study show that at the optimum conditions of 3:1 methanol-oil molar ratio, $0.55 \%$ catalyst loading, and 45-min reaction time, the biodiesel yield was recorded to be $95.28 \pm 0.15 \%$. This high yield of biodiesel concludes that the acid pretreatment of the waste oil of rendered pork was effective in reducing the initial acid value of the oil significantly. Furthermore, the physicochemical characterization of the derived biodiesel indicated significant results as presented in this study, which is a good indicator that the WO-RP was successfully converted into biodiesel with comparable characteristics and properties with the commercial diesel in the market. Thus, the results of this study could potentially impact positively in solving the energy problems faced by the world at present.

\section{Statement of novelty}

This work takes advantage of the utilization of waste oil of rendered pork from a food processing company as a source of high-quality biodiesel, which can be used as a substitute of the company to their LPG in cooking their product. Sustainability, in this sense, can be achieved since the company will utilize its waste to supply fuel for its production. The biodiesel yield was also optimized using the central composite design of the response surface methodology to achieve the optimum conditions for biodiesel production.

\section{Abbreviations}

ANOVA: analysis of variance; ASTM: American Society for Testing and Materials; CCD: central composite design; EN: European Standards; FAME: fatty acid methyl ester; FFA: free fatty acid; FTIR: Fourier Transform Infrared Radiation; GCMS: gas chromatography and mass spectroscopy; HHV: high heating value; RSM: response surface methodology; WO-RP: waste oil of rendered pork.

\section{Acknowledgements}

The authors would like to thank the College of Engineering and Technology of the University of Science and Technology of Southern Philippines - Claveria for the support in conducting this study. Special thanks to the Slers Industries, Inc. for the invaluable support and assistance.

\section{Authors' contributions}

All authors listed have contributed to the conduct and completion of the study. All authors read and approved the final manuscript.

\section{Funding}

This study received no funding. 


\section{Availability of data and materials}

All data generated or analyzed during this study are included in this article.

\section{Ethics approval and consent to participate}

Not applicable.

\section{Consent for publication}

All authors approved the consent for publishing the manuscript to bioresources and bioprocessing

\section{Competing interests}

The authors declare that they have no competing interests.

\section{Author details}

${ }^{1}$ College of Engineering and Technology, University of Science and Technology of Southern Philippines, 9004 Claveria, Philippines. ${ }^{2}$ Intellectual Property Office, University of Science and Technology of Southern Philippines, 9004 Claveria, Philippines.

Received: 24 July 2019 Accepted: 23 November 2019

Published online: 30 November 2019

\section{References}

13th Congress of the Philippines (2006) Biofuels Act of 2006. Republic of the Philippines

Abdullah NH, Hasan SH, Yusoff NRM (2013) Biodiesel production based on waste cooking oil (WCO). Int J Mater Sci Eng. https://doi.org/10.12720/ ijmse.1.2.94-99

Al-Hamamre Z, Yamin J (2014) Parametric study of the alkali catalyzed transesterification of waste frying oil for Biodiesel production. Energy Convers Manag 79:246-254. https://doi.org/10.1016/j.enconman.2013.12.027

Ap R, Turtelli Pighinelli ALM, Jin K (2011) Biodiesel production and quality. In: Bernardes MA (ed) Biofuel's engineering process technology. Rijeka, InTech

Arazo RO, Bayron MC, Abregana VD et al (2016) Production of high quality biodiesel from waste chicken fats. J High Educ Res Discipl 4:58-70

Ashraful AM, Masjuki HH, Kalam MA et al (2014) Production and comparison of fuel properties, engine performance, and emission characteristics of biodiesel from various non-edible vegetable oils: a review. Energy Convers Manag 80:202-228. https://doi.org/10.1016/j.enconman.2014.01.037

Banković-Ilić IB, Stojković IJ, Stamenković OS et al (2014) Waste animal fats as feedstocks for biodiesel production. Renew Sustain Energy Rev 32:238-254. https://doi.org/10.1016/j.rser.2014.01.038

Barabas I, Todoru I-A (2011) Biodiesel quality, standards and properties. In: Montero G, Stoytcheva M (eds) Biodiesel-quality, emissions and byproducts. Rijeka, InTech

Canoira L, Rodríguez-Gamero M, Querol E et al (2008) Biodiesel from low-grade animal fat: production process assessment and biodiesel properties characterization. Ind Eng Chem Res 47:7997-8004. https://doi. org/10.1021/ie8002045

Chai M, Tu Q, Lu M, Yang YJ (2014) Esterification pretreatment of free fatty acid in biodiesel production, from laboratory to industry. Fuel Process Technol 125:106-113. https://doi.org/10.1016/j.fuproc.2014.03.025

Coates J (2000) Interpretation of infrared spectra, a practical approach. Encyc Anal Chem 12:10815-10837

Dias JM, Alvim-Ferraz MCM, Almeida MF (2009) Production of biodiesel from acid waste lard. Bioresour Technol 100:6355-6361. https://doi. org/10.1016/j.biortech.2009.07.025

Diaz-Felix W, Riley MR, Zimmt W, Kazz M (2009) Pretreatment of yellow grease for efficient production of fatty acid methyl esters. Biomass Bioenergy 33:558-563. https://doi.org/10.1016/j.biombioe.2008.09.009

Encinar JM, Sánchez N, Martínez G, García L (2011) Study of biodiesel production from animal fats with high free fatty acid content. Bioresour Technol 102:10907-10914. https://doi.org/10.1016/j.biortech.2011.09.068

Enweremadu CC, Mbarawa MM (2009) Technical aspects of production and analysis of biodiesel from used cooking oil-a review. Renew Sustain Energy Rev 13:2205-2224. https://doi.org/10.1016/j.rser.2009.06.007

Ezekannagha CB, Ude CN, Onukwuli OD (2017) Optimization of the methanolysis of lard oil in the production of biodiesel with response surface methodology. Egypt J Pet 26:1001-1011. https://doi.org/10.1016/j. ejpe.2016.12.004

Feddern V, Cunha A, De Pra MC et al (2011) Animal fat wastes for biodiesel production. In: Rossi M, Amaretti A, Raimondi S, Leonardi A (eds) Biodieselfeedstocks and processing technologies. Rijeka, InTech

Fregolente PBL, Fregolente LV, Wolf Maciel MR (2012) Water content in biodiesel, diesel, and biodiesel-diesel blends. J Chem Eng Data 57:18171821. https://doi.org/10.1021/je300279c

Gumaling RP, Agusan JR, Ellacer NVCR et al (2018) Increased bio-oil yield from Swietenia macrophylla seeds through microwave pretreatment and ultrasonic-assisted solvent extraction. Sustain Environ Res 28:430-437. https://doi.org/10.1016/j.serj.2018.06.003

Hagenow G, Reders K, Heinze H-E et al (2010) Fuels. In: Mollenhauer K, Tschoeke $\mathrm{H}$ (eds) Handbook of diesel engines. Springer, Berlin, pp 77-125

Ibrahim AP, Omilakin RO, Betiku E (2019) Optimization of microwave-assisted solvent extraction of non-edible sandbox (Hura crepitans) seed oil: a potential biodiesel feedstock. Renew Energy. https://doi.org/10.1016/j. renene.2019.04.010

Issariyakul T, Kulkarni MG, Dalai AK, Bakhshi NN (2007) Production of biodiesel from waste fryer grease using mixed methanol/ethanol system. Fuel Process Technol 88:429-436. https://doi.org/10.1016/j.fupro c.2006.04.007

Kibasi T (2018) Time for change. IPPR Progressive Rev 25:133-136. https://doi. org/10.1111/newe.12104

Knothe G, Steidley KR (2005) Kinematic viscosity of biodiesel fuel components and related compounds. Influence of compound structure and comparison to petrodiesel fuel components. Fuel 84:1059-1065. https://doi. org/10.1016/j.fuel.2005.01.016

Kumar D, Ali A (2010) Nanocrystalline lithium ion impregnated calcium oxide as heterogeneous catalyst for transesterification of high moisture containing cotton seed oil. Energy Fuels 24:2091-2097. https://doi. org/10.1021/ef901318s

Kumar A, Shukla SK, Tierkey JV (2016) A review of research and policy on using different biodiesel oils as fuel for C.I. engine. Energy Procedia 90:292-304. https://doi.org/10.1016/j.egypro.2016.11.197

Lam MK, Lee KT, Mohamed AR (2010) Homogeneous, heterogeneous and enzymatic catalysis for transesterification of high free fatty acid oil (waste cooking oil) to biodiesel: a review. Biotechnol Adv 28:500-518. https:// doi.org/10.1016/j.biotechadv.2010.03.002

Lane J (2016) Biofuels mandates around the world: 2016. BiofuelsDigest

Lin C-Y, Lin Y-W (2012) Fuel characteristics of biodiesel produced from a highacid oil from soybean soapstock by supercritical-methanol transesterification. Energies 5:2370-2380. https://doi.org/10.3390/en5072370

Mabayo VIF, Aranas JRC, Cagas VJB et al (2018) Optimization of oil yield from Hevea brasiliensis seeds through ultrasonic-assisted solvent extraction via response surface methodology. Sustain Environ Res 28:39-46. https://doi. org/10.1016/j.serj.2017.08.001

Macedo TDO, Pereira RG, Pardal JM et al (2013) Viscosity of vegetable oils and biodiesel and energy generation. Int J Chem Mol Eng 7:251-256

Mansir N, Teo SH, Rashid U et al (2018) Modified waste egg shell derived bifunctional catalyst for biodiesel production from high FFA waste cooking oil. A review. Renew Sustain Energy Rev 82:3645-3655. https://doi. org/10.1016/j.rser.2017.10.098

Meena Devi R, Subadevi R, Paul Raj S, Sivakumar M (2015) Comparative studies on biodiesel from rubber seed oil using homogeneous and heterogeneous catalysts. Int J Green Energy 12:1215-1221. https://doi. org/10.1080/15435075.2014.893879

Pan H, Li H, Zhang H et al (2018) Effective production of biodiesel from nonedible oil using facile synthesis of imidazolium salts-based BrønstedLewis solid acid and co-solvent. Energy Convers Manag 166:534-544. https://doi.org/10.1016/j.enconman.2018.04.061

Prankl H, Körbitz W, Mittelbach M, Wörgetter M (2004) Review on biodiese standardization world-wide

Refaat AA (2009) Correlation between the chemical structure of biodiesel and its physical properties. Int J Environ Sci Technol 6:677-694. https://doi. org/10.1007/BF03326109

Russel A (2003) Combustion emissions. In: Air pollution and cancer, pp 37-47

Sahar Sadaf S, lqbal J et al (2018) Biodiesel production from waste cooking oil: an efficient technique to convert waste into biodiesel. Sustain Cities Soc 41:220-226. https://doi.org/10.1016/j.scs.2018.05.037 
Sander A, Antonije Košćak M, Kosir D et al (2018) The influence of animal fat type and purification conditions on biodiesel quality. Renew Energy 118:752-760. https://doi.org/10.1016/j.renene.2017.11.068

Shaftel H, Jackson RSC (2016) A blanket around the earth. In: NASA

Shalaby EA, El-gendy NS (2012) Two steps alkaline transesterification of waste cooking oil and quality assessment of produced biodiesel. Int J Chem Biochem Sci 1:30-35

Sun S, Guo J, Duan X (2019) Biodiesel preparation from Phoenix tree seed oil using ethanol as acyl acceptor. Ind Crops Prod 137:270-275. https://doi. org/10.1016/j.indcrop.2019.05.035

US Energy Information Administration (2017) International energy outlook 2017

Verma D, Raj J, Pal A, Jain M (2016) A critical review on production of biodiesel from various feedstocks. J Sci Innov Res 5:51-58
Yesilyurt MK (2019) The effects of the fuel injection pressure on the performance and emission characteristics of a diesel engine fuelled with waste cooking oil biodiesel-diesel blends. Renew Energy 132:649-666. https:// doi.org/10.1016/j.renene.2018.08.024

Zhang Q, Wei F, Ma P et al (2018) Mesoporous Al-Mo oxides as an effective and stable catalyst for the synthesis of biodiesel from the esterification of free-fatty acids in non-edible oils. Waste Biomass Valoriz 9:911-918. https :/doi.org/10.1007/s12649-017-9865-5

\section{Publisher's Note}

Springer Nature remains neutral with regard to jurisdictional claims in published maps and institutional affiliations.

\section{Submit your manuscript to a SpringerOpen ${ }^{\circ}$ journal and benefit from:}

- Convenient online submission

- Rigorous peer review

- Open access: articles freely available online

- High visibility within the field

- Retaining the copyright to your article

Submit your next manuscript at $\boldsymbol{\sim}$ springeropen.com 